\title{
PIA and rSesC Mixture Arisen Antibodies Could Inhibit the Biofilm-Formation in Staphylococcus aureus
}

\author{
Bahman Mirzaei*1,2, Ryhane Babaei ${ }^{1,2}$, Mohammad Reza Haghshenas ${ }^{1}$, \\ Fatemeh Mohammadi ${ }^{2}$, Pegah Homayoni ${ }^{2}$, Ebrahim Shafaei ${ }^{3}$
}

\begin{abstract}
Background: Staphylococcus aureus as a causative agent of hospital-acquired infections has been considered as the primary concern in biomaterial-related infections (BAIs).

Methods: Following the purification of polysaccharide intercellular adhesion (PIA) as an efficient macromolecule in biofilm formation in the native condition, recombinant $S$. epidermidis surface-exposed $\mathrm{rSesC}$ protein, with the most homology to clumping factor A (ClfA) in S. aureus was cloned and expressed in a prokaryotic host as well. Fourier transform infrared spectrometry (FTIR) and Western blotting procedure analyzed purified PIA and protein, respectively. Then, the immune response was evaluated by measuring total IgG titers. Moreover, the capacity of Anti-biofilm forming activity of arisen antibodies to a biofilm-forming $S$. aureus strains was assessed by the semi-quantitative micro-plate procedure.

Results: Data showed that the total IgGs were boosted in mice immunized sera. By performing an inhibition assay, the biofilm inhibitory effect of secreted antibodies to test strain was observed. Arisen antibodies against the mixture significantly were more potent than PIA and rSesC, when comparing individual antigens in a biofilm inhibition assay.

Conclusions: immunization of mice with mentioned antigens especially a mixture of them, could eliminate the biofilm formation process in $S$. aureus. Hopefully, this study corresponds to the suggestion that the immunization of mice with PIA and rSesC candidate vaccines could protect against $S$. aureus infection.
\end{abstract}

Keywords: PIA, Purification, Staphylococcus aureus, rSesC, Vaccine candidates.

\section{Introduction}

Staphylococci are opportunistic pathogens and determined as the most common causes of infections related to implanted medical devices, infect both hospitalized patients and immunocompromised individuals (1). Diverse Staphylococcal virulence factors, such as capsule and cell wall-bound adhesion molecules, surface proteins, toxins, antibiotic resistance, and biofilm formation cause infections in humans and animals (2-3). S. aureus is an etiological agent of the mild to severe infections in hospitalized patients, such as bacteremia due to endocarditis, pneumonia, and metastatic infections. Findings revealed that the majority of adults are either permanently or transiently susceptible to colonization by $S$. aureus (4). Up to $20-30 \%$ of humans, asymptomatically are colonized by $S$. aureus and 50-60\% of those are intermittently colonized $(5,6)$. Since the 1960 s, first (MRSA) strains were detected and with worldwide spreading, becoming a global major challenge. Despite the importance of this bacterium in human and animal infections, there are no available vaccines to prevent $S$. aureus infections yet (7). The contamination of medical devices with $S$. aureus during insertion might be 
remarkably depended on the patient health care personal. Although there is some similarity in biofilm-associated infections with $S$. aureus and $S$. epidermidis, more intensive care is needed for the involvement of $S$. aureus. S. aureus biofilmassociated infections are more difficult to be treated by antibiotic therapy, and the devices need to get replaced more frequently $(8,9)$. The Ica operon of Staphylococcus spp encodes the production of polysaccharide intercellular adhesion (PIA), also known as poly- $\mathrm{N}$-acetyl glucosamine (PNAG) (10). The PIA-dependent mechanism is the best-understood mechanism of biofilm formation. Cerca et al. demonstrated that rabbit anti-PIA antibodies protect against infections with planktonic cells of PIA-positive S. aureus and S. epidermidis (11). Based on a study by Maira-Litran et al., anti-dPIA antibodies are mediated opsonic killing and protected against $S$. aureus infection (12). Recent studies indicate the presence of the other proteinaceous mechanisms of biofilm formation. Shahrooei revealed that monoclonal antibodies against $S$. epidermidis surface exposed Ses proteins can significantly reduce the accumulation phase (13). Clumping factor A (ClfA) is a fibrinogen (Fg) -binding microbial surface molecule recognizing adhesive matrix molecules (MSCRAMM) of S. aureus; $65.1 \%$ similarity has been shown between SesC and a 341-aa fragment of ClfA (14).

Owing to the vital biofilm-forming capacity role in the chronic staphylococcal disease development, evaluation of the biofilm inhibitory effect of PIA and recombinant SesC antibodies against a biofilm-forming $S$. aureus, separately and in a mixture, form was targeted as the main goal of this study.

\section{Materials and Methods \\ Bacterial strains}

Purification of the PIA and related procedure were accomplished by applying two biofilmforming S. epidermidis strains, ATCC 14990 and 35984, also known as 1457 and RP62A, a trans mutant strain, 1457-M10, and a wild type biofilm-forming S. aureus strain. Moreover, Escherichia coli strain BL21 (DE3) was served as a prokaryotic host to DNA manipulation and recombinant protein production.

\section{Construction and purification of His-tagged rSesC protein}

Based on the reported procedure (14) a 1,359-bp fragment of SesC encoding a 459-aa extracellular part of SesC containing a six-His-tag at the Cterminus was amplified. In short, following the cloning and expression of the representative sequence in a prokaryotic host, 55KD rSesC protein was determined by SDS-PAGE and Coomassie Brilliant Blue staining. Protein was expressed in Escherichia coli BL21 DE3 following the induction by $1 \mathrm{mM}$ imidazole in optical density $0.7-0.9$ in a shaker incubator (150 $\mathrm{rpm}$ at $37{ }^{\circ} \mathrm{C}$ for 3 hours). Purifying of the recombinant protein was done using the commercial affinity chromatography Kit (GE health care, Sweden) according to the manufacture's recommendation followed by extraction of soluble protein from induced host using sonication (4 times for $30 \mathrm{~s}$ on ice) with an additional centrifugation $(17709 \mathrm{G}$ for $20 \mathrm{~min}$ at $4{ }^{\circ} \mathrm{C}$ ) to the clarification of the targeted protein. The purity of the recombinant protein was determined by Coomassie blue staining of a sodium dodecyl sulfate-polyacrylamide gel electrophoresis gel then analyzed by western blotting. The expression of the protein was done as follows: E. coli BL21 (DE3) cells were transformed with the vector. Cells were grown with shaking at $250 \mathrm{rpm}$ at $37{ }^{\circ} \mathrm{C}$ in Luria-Bertani broth with $100 \mathrm{~g} / \mathrm{ml}$ ampicillin to an optical density at $600 \mathrm{~nm}$ of 0.6 to 0.8 . Isopropyl-DThiogalactopyranoside (IPTG) in $1 \mathrm{mM}$ as a final concentration was added on media to the induction of protein expression. Following cooling on ice, cells were collected by centrifugation at $7871 \mathrm{G}$ for $5 \mathrm{~min}$ at $4{ }^{\circ} \mathrm{C}$, resuspended in imidazole buffer, and frozen at $20{ }^{\circ} \mathrm{C}$. Harvested pellets were sonicated three times for $30 \mathrm{~s}$ on ice. The expressed protein was determined by SDS-PAGE and Coomassie brilliant blue staining. (Fig. 1A). 

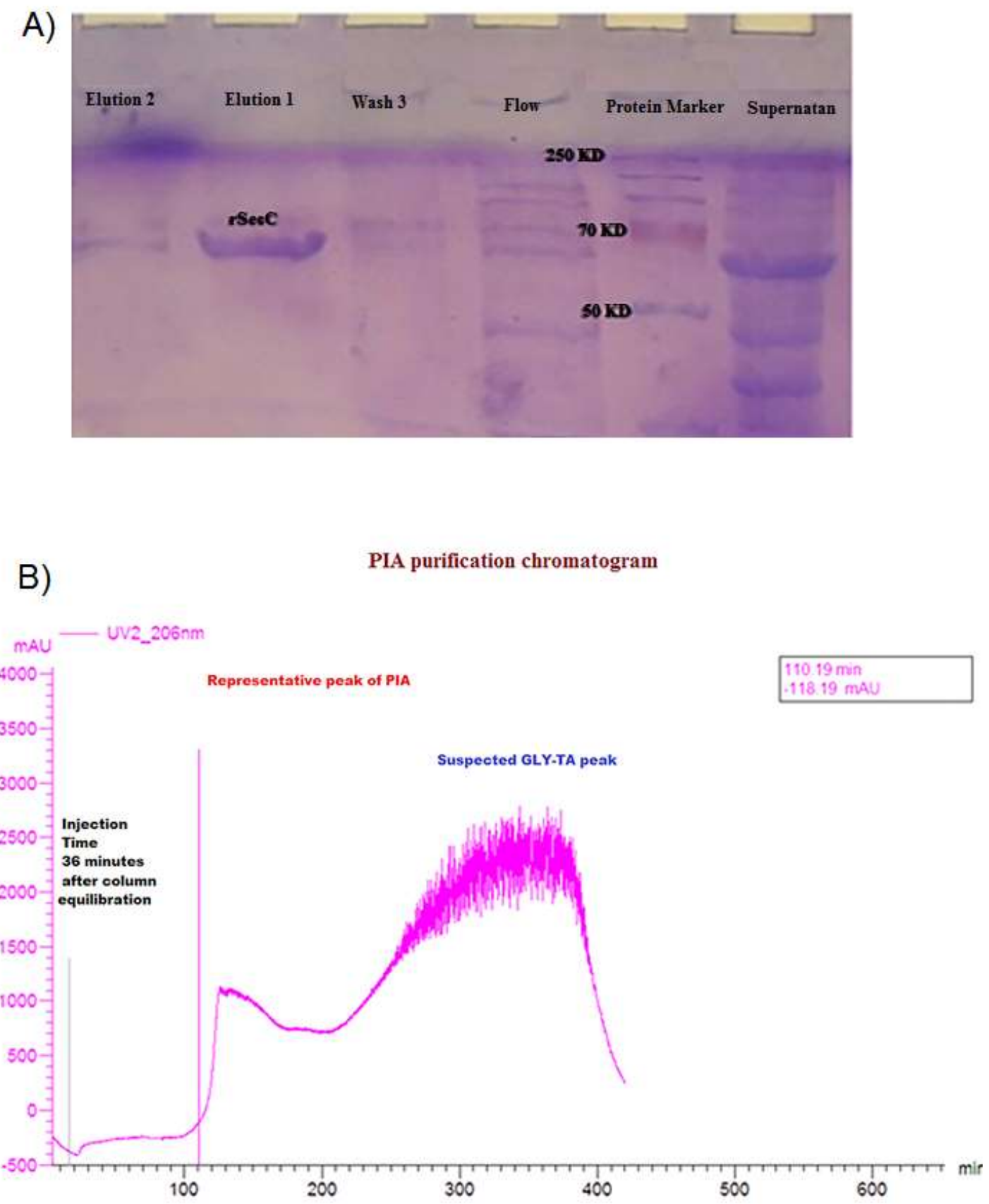

Fig. 1. Purification of PIA by affinity and size exclusion chromatography. A) Purification of truncated recombinant protein (rSeC) taking advantage of SDS-PAGE procedure, purified protein in $55 \mathrm{KD}$ protein size was eluted (elution 1) and related rSesC protein size was compared with pre stained protein marker. B) Representative Fast protein liquid chromatography (FPLC) chromatogram for native PIA. Sample in $1 \mathrm{ml}$ final volume was injected after 36 minutes column equilibration. PIA was eluted near the void volume following the 110 minutes after sample injection by using $0.3 \mathrm{ml} / \mathrm{min}$ flow rate. Polysaccharide was identified at a wavelength of $206 \mathrm{~nm}$.

\section{Extraction and purification of native PIA}

PIA was purified as previously described (1517). Briefly, the cells were harvested from incubated $\left(37^{\circ} \mathrm{C}\right.$ for $24 \mathrm{~h}$ with shaking at 40 $50 \mathrm{rpm} / \mathrm{min}$ ) 2 liters of trypticase soy broth (TSB) by centrifugation $(40-50 \mathrm{G} / \mathrm{min}$ for 20 min at $4{ }^{\circ} \mathrm{C}$ ) and were re-suspended in $20 \mathrm{ml}$ of
$50 \mathrm{mM}$ sodium phosphate buffer ( $\mathrm{pH} 7.5)$. After that, the suspended colonies were sonicated four times for $30 \mathrm{~s}$ on ice. The extracts were cleaned up by centrifugation at $17709 \mathrm{G}$ for 15 $\min$ at $4{ }^{\circ} \mathrm{C}$. The supernatant was dialyzed overnight in a $12 \mathrm{KD}$ dialysis bag against the 
same buffer and concentrated using Centriprep 10 (Amicon, Witten, Germany). The soluble proteins were eliminated by proteinase-K, then the sample was directly loaded onto an equilibrated 1.6 x $100 \mathrm{~cm}$ Sephacryl S-100 column (Pharmacia LKB GmbH, Freiburg, Germany) with $50 \mathrm{mM}$ sodium phosphate. In the end, purified PIA was stored at $-20{ }^{\circ} \mathrm{C}$ in Amicon cell (Fig. 1B). The concentration of the purified PIA was assessed via the amount of hexosamine, taking advantage of the 3-methyl2-benzothiazolone hydrazine hydrochloride method with $\mathrm{N}$-acetyl glucosamine as standard (18). (Fig. 2B).

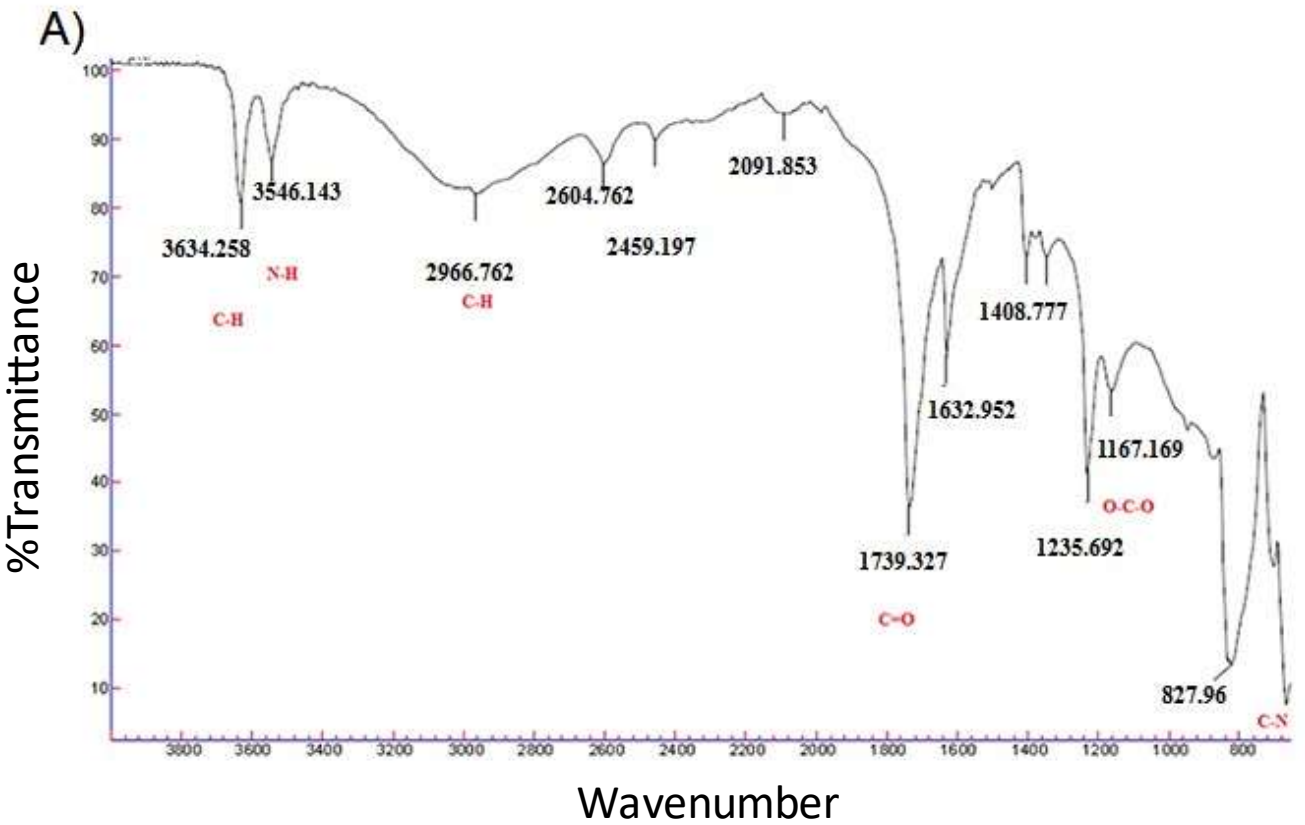

B)

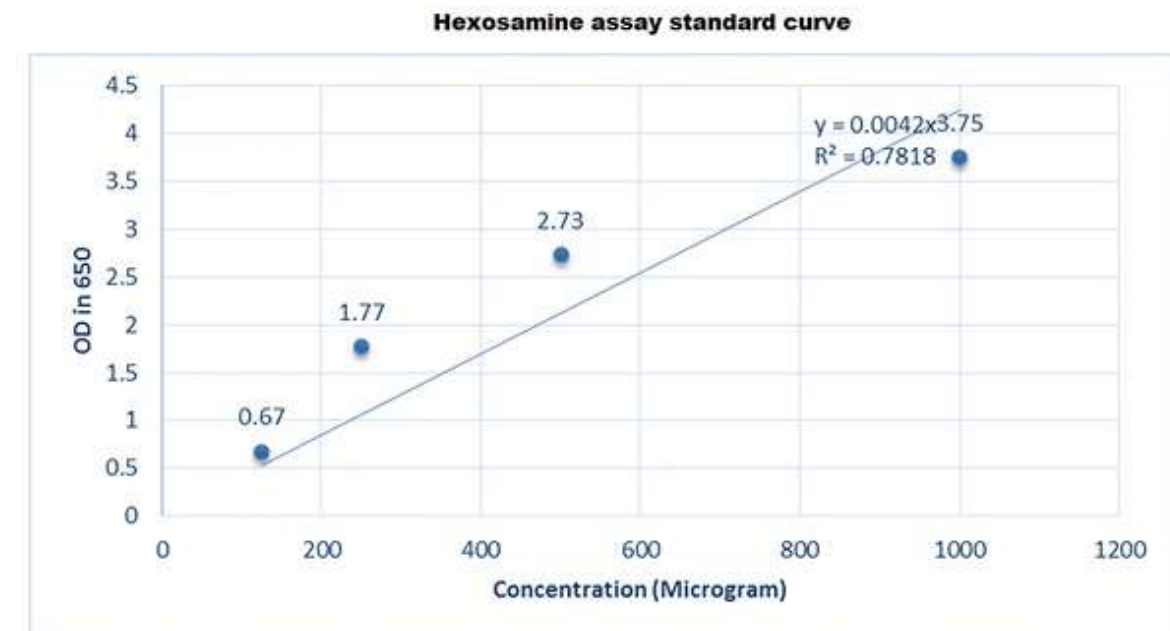

Fig. 2. Reconfirmation of purified PIA structure by FTIR and its hexosamine content. A) IR spectra of Purified PIA in the $4000-500 \mathrm{~cm}-1$ range and the result of this deconvolution. Infrared spectroscopy of purified polysaccharide was investigated using the regularized method of deconvolution. According to the composition of the PIA molecules $\mathrm{C}=\mathrm{O}$ groups in 1739.327 of the native polysaccharides in the FTIR pattern, was detected. B) Standard curve to hexosamine assay. According to the procedure, three concentrations $(\mu \mathrm{g} / \mathrm{ml})$ of $\mathrm{N}$-acetylglucosamine as standard were used and optical density of these concentrations evaluated in $650 \mathrm{~nm}$. 


\section{Biochemical analysis}

The amount of protein content in the purified rSesC was assessed by the Bradford assay (16). The constitution and structure of the purified native PIA were analyzed using Fourier transform infrared spectroscopy (FTIR) and colorimetric assays. (Fig. 2A).

\section{Pyrogenicity test and general safety}

Taking advantage of the previous procedure, the pyrogenicity and toxicity of the antigens were checked (19). The amount of endotoxin in the prepared antigens was measured by a commercial Limulus amebocyte lysate kit (Thermo Scientific, Waltham, MA, USA) according to the manufacturer's recommendations.

\section{Immunization of mice}

6-8-week-old female $18 \pm 2 \mathrm{~g}$ BALB/c inbred mice (purchased from the Research Institution of Pasteur Karaj, IR Iran) were divided into four groups of six mice each for the vaccination experiments. The mice were housed in standard stainless cages at $23-25{ }^{\circ} \mathrm{C}$ and $60-70 \%$ humidity, with a $12 \mathrm{~h}$ light/dark cycle, for a week before the experience. The mice were given free access to a standard diet and water. Each mouse in the specific group was immunized thrice subcutaneously with the respective lyophilized antigens (PIA, rSesC, PIA/ rSesC, and PBS) in $1 \%$ alum (Brentag, Denmark) dissolved in PBS (filtered at $0.22 \mathrm{~nm}$ pore diameter). The amount of candidate vaccines dosage was adjusted to a concentration of PIA and protein in the mixture then immunogenicity of candidate vaccines was compared to control. After two weeks of each immunization (immunization days were $0,7,14$ and 28) $500 \mu$ l of peripheral blood was collected from the tail vein of five mice in each group. Collected sera were stored at $-20^{\circ} \mathrm{C}$ followed by centrifugation (1107 $\mathrm{G}$ for $5 \mathrm{~min}$ ) of peripheral blood (20).

The experimental groups were as follows:

G-1: The negative control group, which was not subject to immunization at all.

G-2: The PIA immunized group, in which immunized with $100 \mu \mathrm{g}$ with PIA.
G-3: The rSesC immunized group, in which immunized with $25 \mu \mathrm{g}$ with purifies rSesC.

G-4: PIA/rSesC mixture group, in which, mice were immunized with PIA/RSesC at a concentration of $72.25 \mu \mathrm{g}$.

G-5: Positive control group, in which samples were not immunized.

\section{Ethics Statement}

All animal experiments were performed under the enlarged ethical statement and approved by Mazandaran University of Medical Sciences ethics committee. All performed on the enlarged ethical statement IR.MAZUMS.REC.1397.55 meeting number in Mazandaran University of Medical Sciences. Inbred mice were purchased from the Research Institution of Pasteur, Karaj, Iran. Using the halogenated ether procedure as an inhalant anesthetic, mice were euthanized as well. In short, mice encountered an Inhalant ether overdose (up to 2-5\% to effect) (21).

\section{Enzyme-linked Immunosorbent Assay (ELISA)}

Anti-PIA antibodies were introduced into the immunized mice sera by applying a commercial enzyme-linked immunosorbent assay after each immunization. Briefly, 96-well plates (Extra gene, USA) were coated overnight with $100 \mu \mathrm{l}$ of PIA $(1 \mu \mathrm{g} / w e l l)$ in PBS at $4{ }^{\circ} \mathrm{C}$. Then, the plates were washed three times with washing buffer [0.05\% (v/v) Tween 20 in PBS], followed by blocking with PBS/Tween 20 containing 5\% bovine serum albumin (BSA) for $2 \mathrm{~h}$ at $37^{\circ} \mathrm{C}$. Fling blocking and washing, the mouse sera were (1: 2 to $1: 1024)$ in blocking buffer and 100 $\mu 1$ of the samples were added to the wells in duplicate. The plates were incubated for $2 \mathrm{~h}$ at 37 ${ }^{\circ} \mathrm{C}$, washed three times and incubated with HRPconjugated anti-mouse IgG (Sigma, USA) diluted to 1: 10000 (as a secondary antibody) at $37{ }^{\circ} \mathrm{C}$ for $2 \mathrm{~h}$. The plates were washed as described above; enzymatic activity was measured by adding $100 \mu \mathrm{l}$ of tetramethylbenzidine (TMB) substrate.

After 30 min subjoining $100 \mu \mathrm{l}$ of $2 \mathrm{~N} \mathrm{H} 2 \mathrm{SO} 4$ the reaction was stopped. Detailed data related to the arisen antibodies is shown in Figure 3. 


\section{Booster effect}

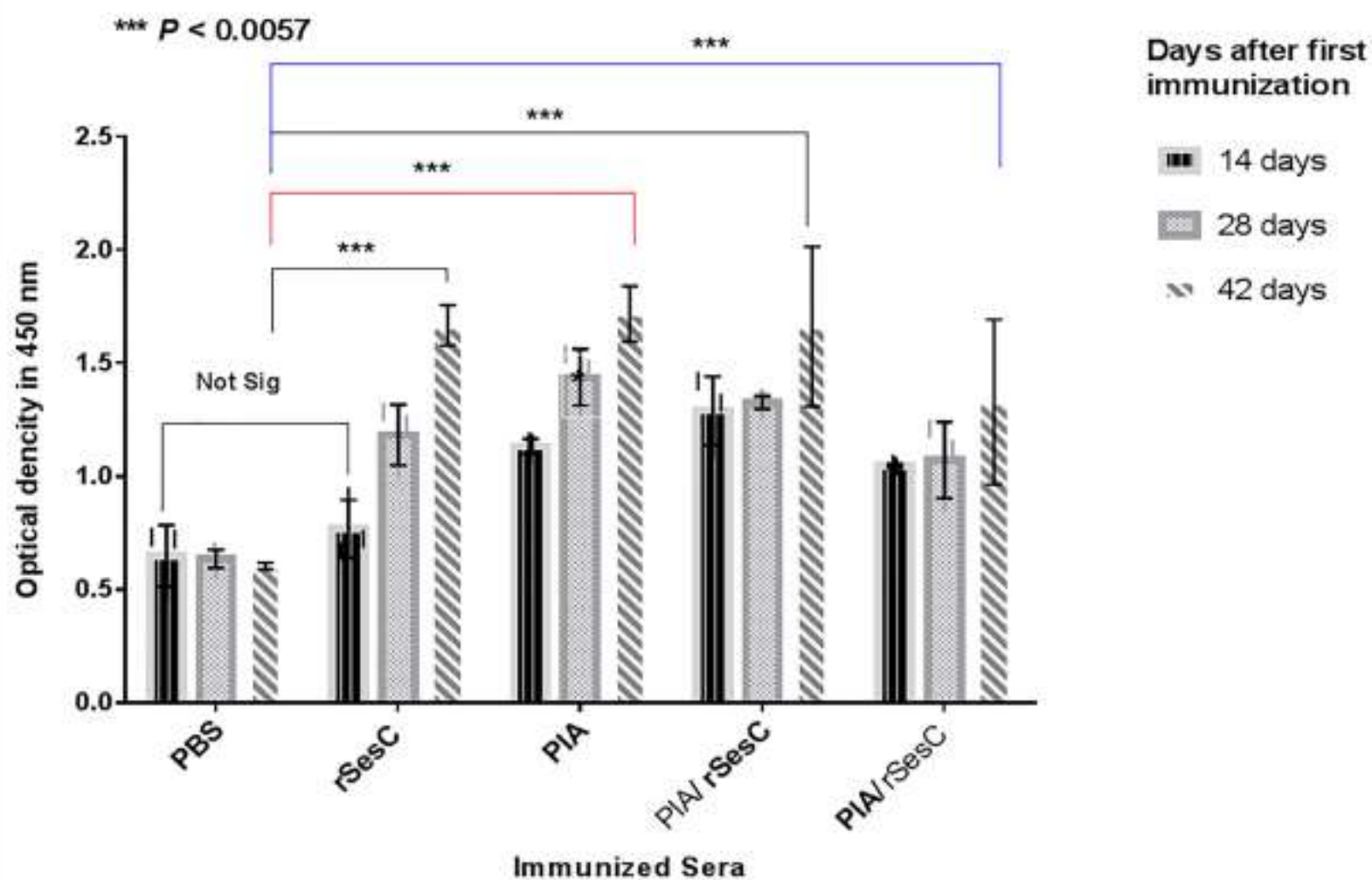

Fig. 3. Total arisen antibodies to antigens. The booster effect of the assessed antigens at different times. ELISA was performed by coating the native PIA and rSesC. The titers of the antibodies were assessed for immunized sera compared to the controls. Significant effects were observed from use of the mixture and conjugate booster. Six weeks after the first injection, the titers of antibodies had increased. Antibody titration was assessed in 1: 200 titer, the error bar is representative of the mean $\pm S D(n=3)$.

\section{In vitro Biofilm Inhibition Assay}

Biofilm inhibitory effect of pre- and post-immune IgGs against injected antigens on in vitro biofilm formation was analyzed using a semi-quantitative microtiter plate method (22). In short, $5 \times 10^{5}$ $\mathrm{CFU} / \mathrm{ml}^{-1}$ of an overnight culture of $S$. aureus grown in BHI for the initial attachment in fresh sterile trypticase soy supplemented by $1 \%$ glucose (TSBg) broth was prepared. A while later, in a polystyrene microtiter plate (Corning Joined Life Sciences, Lowell, MA, USA), a mixture of $200 \mu \mathrm{l}$ of diluted bacterial cultures and $50 \mu \mathrm{l}$ of a twofold diluted post and pre-immunized mouse sera were inoculated into three parallel wells. After incubation at $37{ }^{\circ} \mathrm{C}$ for $20 \mathrm{~h}$, respectively, the attached cells and biofilm were stained by crystal violet as previously described (24). The OD at 595 (OD595) of the dissolved stain in $160 \mu \mathrm{l}$ of $30 \%$ (vol $/ \mathrm{vol}$ ) acetic acid was measured in amultipurpose UV/VIS plate reader. Negative control of sterile TSBg without bacteria was included and the assay was repeated independently three times. A previously described in vitro biofilm formation assay was also performed (23).

The percentage inhibition of biofilm formation was calculated using the following formula:

(A 595, positive -A 595, antibody) / (A 595, positive - A 595, negative) $\times 100$ (24) (Fig. 4)

\section{Statistical Analysis}

Utilizing A Two-way multiple- group analysis of variance (ANOVA) by a graph pad software, statistical analysis of results was accomplished and a p-value $<0.05$ was considered significant. 


\section{Biofilm inhibition assay}

$$
\begin{aligned}
& { }^{* *} P<0.0004 \\
& { }^{*} P<0.05
\end{aligned}
$$

Days after first immunization

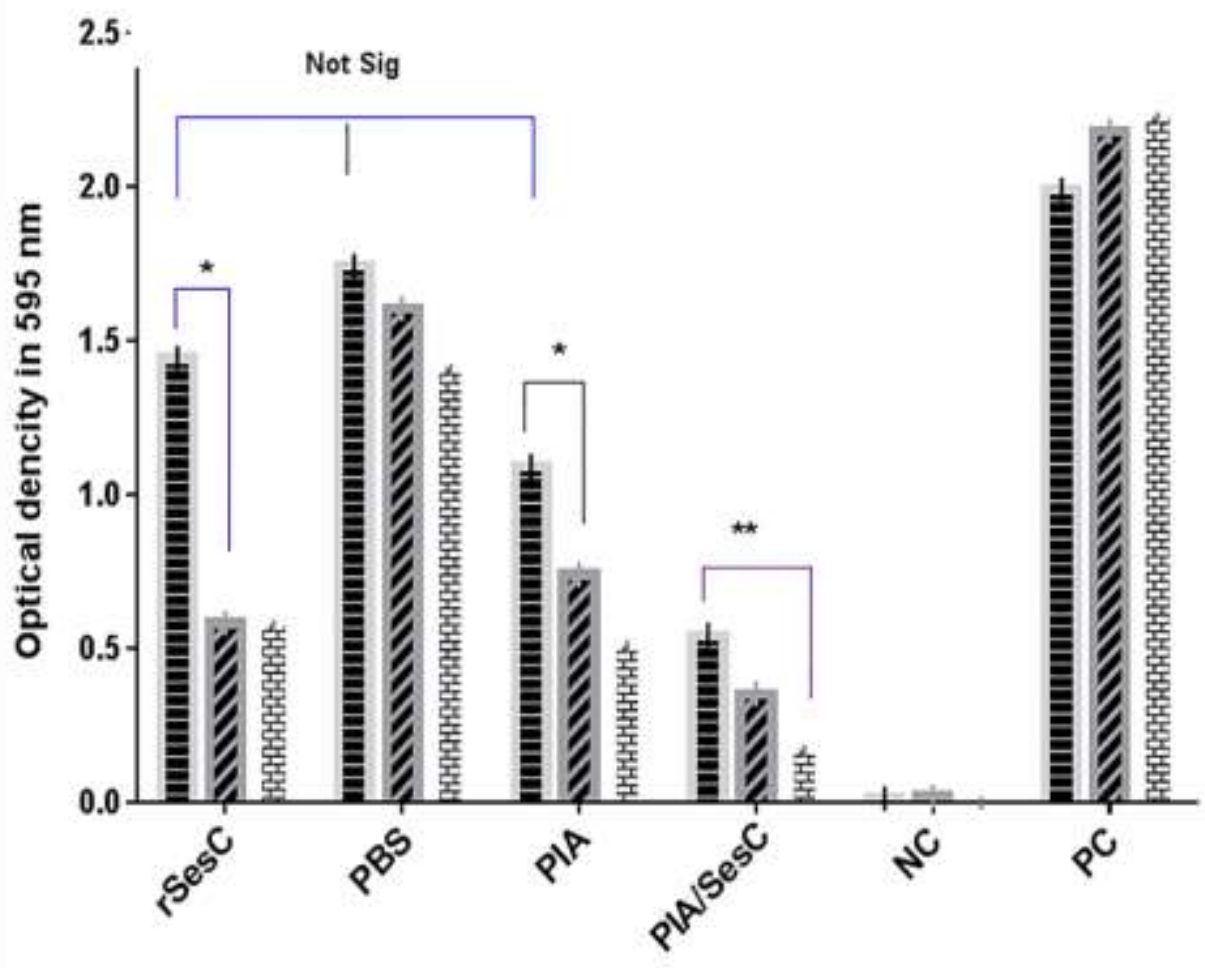

14 days

28 days

由 42 days

\section{Immunized Sera}

Fig. 4. Biofilm inhibition assay by comparing diluted sera. The biofilm-inhibitory effects of increasing antibodies (after each shot) were determined by comparing the positive and negative controls using the mentioned formula. The error bar is representative of the mean $\pm \operatorname{SD}(n=3)$.

\section{Results}

\section{Purification of Macromolecules}

The expressed protein was purified taking advantage of affinity chromatography procedure. Representative rSesC protein was confirmed based on the size by SDS- PAGE procedure. Then the presence of a C-terminal Hexa-His- tagged residue in the protein was determined by a Western blot Following the Bradford assay procedure. The amount of the purified protein was assessed about $5 \mathrm{mg}$.

\section{Purification of PIA}

PIA as the main compartment of biofilmforming macromolecule in the aggregation phase was purified based on the native condition procedure using a size exclusion chromatography procedure. To isolate PIA (100 KD), size-exclusion chromatography was performed by Sephacryl S-100. PIA was purified at a flow rate of $0.300 \mathrm{ml} \mathrm{min}-1$ and fractions of $1.5 \mathrm{ml}$ were collected every $5 \mathrm{~min}$ in a fraction collector. Contaminated PIA by proteins and nucleic acid (RNA and DNA) was cleaned by enzymatic digestion too. Chemical analysis of purified PIA indicated negligible contamination $(<2 \%$ protein and $<0.4 \%$ nucleic acids). Subsequently based on the colorimetric assay procedure by targeting the $\mathrm{N}$-acetyl Glucosamine residue in the compartment, data showed that the purified PIA contained $65 \%$ hexosamine $(5700 \mu \mathrm{g} \mathrm{ml}-1)$, uronic acid $(29 \mu \mathrm{g}$ $\mathrm{ml}-1)$ and ketose (170 $\mu \mathrm{g} \mathrm{ml}-1)$. The 
composition and structure of the PIA were confirmed by using the FTIR procedure.

\section{Endotoxin contents and general safety}

According to the Limulus amebocyte lysate test to purified macromolecules, the content of endotoxin was determined as $4.5 \mathrm{EU} \mathrm{ml}^{-1}$. Pyrogenicity and toxicity were not observed following in vivo challenge.

\section{Anti-antigens Humoral Response}

Using antigen mediated ELISA to evaluate the total IgG antibody response against PIA in the antigen mixture, mice sera antibodies titers were determined $(\leq 1: 200)$. Following the first immunization by rSesC and PIA $(p=0.0057)$, low-level IgGs production comparing to the control group was observed and this amount determined as not significant to $\mathrm{rSesC}$ immunized sera. An increase in IgG titers to PIA $(p=0.0004)$ and $\mathrm{rSesC}(\mathrm{p}=0.0025)$ was observed following the first booster. The third group of mice received a mixture of PIA and rSesC and an increase in anti-PIA antibodies was observed following the second immunization $(\mathrm{p}<0.0001)$.

\section{Biofilm Inhibition Assay by Microtiter plate}

The biofilm inhibition assay was performed by comparing pre-post immune sera by the semiquantitative procedure. Experiments were observed with sera from mice that were boosted after specific periods (14, 28 and 42 days) and results were obtained by comparing the immunized and non-immunized sera, respectively. The data showed that those immunized mice sera by PIA antigen provide significant $(p>0.05)$ inhibition after the first booster dosage. The biofilm inhibitory effects of immunized sera after first boosted dosage by rSesC ( $p>0.0314)$ and $\mathrm{rSesC}$ mixture, $(\mathrm{p}>$ 0.0015 ) and second booster dosage statistically were significant. The obtained data showed that vaccinated mice sera by PIA and rSesC antigens compared to the control group have an insignificant biofilm inhibitory effect after the first immunization (14 days). However, this effect for immunized sera by PIA/rSesC mixture $(p=0.0004)$ was significant when compared by the control sera.

\section{Discussion}

S. aureus as a main human pathogen because of its ability to biofilm formation and antibiotic resistance pattern has been assigned as an essential concern in the worldwide healthcare system (24). Staphylococcus species especially $S$. aureus and S. epidermidis despite being a part of human normal flora, with the ability to surface attachment of medical devices and developing into recalcitrant community multilayered structures, referred to as "biofilm", makes them problematic (18). Biofilm forming ability is a surveillance factor in Staphylococcus spp., mediating the adherence of bacterial cells to biomaterials and helps organisms to avert the host immune defense (18). Staphylococcal ability to biofilm formation is considered as the most important factor triggered in the pathogenesis, and its colonization on medical devices makes it increasingly resistant not only to multiple antibiotics but also to host defenses. There is an essential need to change the medical devices after $S$. epidermidis biofilm infection, and experimental studies on biofilm-preventing vaccines are necessary (25). The role of PIA and proteins in biofilm formation has been demonstrated. Targeting of the SesC protein and PIA macromolecules involved in attachment and accumulation of biofilmforming phase and antibodies that arise in response to them may be suitable options for antibodies-dependent treatment of biofilms (18). In the current study, the evaluation of arisen antibodies against PIA and rSesC protein, the efficacy of antibodies to biofilm inhibition process and putative vaccine candidate activity against the mentioned antigens of $S$. aureus have been listed as the main purposes. Taking advantage of the cloning procedure, rSesC protein was generated and precisely confirmed by the Western blotting method. DNA sequence of the truncated protein representative of the anchor site on the SesC protein was inserted into a cloning vector and transformed into the 
prokaryotic host. The 55KD protein representative of $\mathrm{rSesC}$ was previously purified $(15,26)$. Our results were confirmed when compared to other studies. The specific function of the SesC proteins hadn't described. Closest homologous protein to $\mathrm{SesC}$ is a 341 aa fragment nominated Clumping factor $\mathrm{A}$ in $\mathrm{S}$. aureus) with a specific function (Identity $26.6 \%$ and Homology $65.11 \%$ ) (14). Because of this homology, immunological aspects of SesC protein were targeted to biofilm-forming $S$. aureus too. The published data demonstrate that the arisen antibody to immunized animals with conjugated deacetylated PNAG (15\% acetyl) to diphtheria toxoid (DT) as a carrier protein showing a killing activity against three strains of $S$. aureus and a PIA dependent biofilm-forming S. epidermidis M187 (13).

Because of this homology, the biofilm inhibitory effect of the arisen antibodies to rSesC was targeted to biofilm-forming $S$. aureus. Based on the results, rSesC protein has been determined as the suitable biofilm inhibitory candidate vaccine following the injection of 25 $\mathrm{mg} / \mathrm{ml}$ of the mentioned antigens in mice. This protein not only led to the rise of the specific antibodies after the first booster, but also the biofilm inhibitory effect of raised antibodies was confirmed. Though the occurrence of the mentioned antibodies was not significant when compared to the first immunization (14/28 days) the amount of antibodies compared to the second booster was significantly increased. Raised antibodies against $\mathrm{rSesC}$ protein, as an $S$. aureus clumping factor A protein homolog, successfully decreased biofilm formation in a biofilmforming wild type $S$. aureus comparing the collected sera after injection times. Our results showed that $\mathrm{rSesC}$, due to the biofilm inhibitory effect, separately could be a vaccine candidate against biofilm-forming $S$. aureus. Taking advantage of reported findings (24), although rSesC and PIA were described as two effective vaccine candidates in biofilm-forming $S$. epidermidis, the conjugation of PIA to rSesC will enhance the opsonic activity of secreted antibodies, too. In this study, a mixture of $\mathrm{rSesC}$ and PIA was prepared the occurrence of antibodies against the biofilm-forming wild type
S. aureus were assessed as well. Findings support the hypothesis that rSesC could be considered as a suitable candidate vaccine against biofilm-forming $S$. aureus, too.

PIA as the main component of bacterial accumulation during biofilm formation was extracted from wild-type strain 1457 based on the native purification process. The composition of purified PIA confirmed by FTIR revealed that our obtained data correspond with the other relevant study's findings. We tried to evaluate the PIA and rSesC efficacies as immunoprophylaxis and immunotherapy against biofilm-forming $S$. aureus. According to the studies, the purity of native purified PIA can elicit an antibody response against the mentioned antigen $(18,26-$ 28). Though the antigenicity of most polysaccharides is poor, the increased antibodies to PIA have shown a biofilm inhibitory effect. Corresponding antigens had previously been analyzed as a useful candidate vaccine against biofilm-forming $S$. epidermidis, but the opsonic rate of the rSesC protein was lower in purified IgGs.

In this study, 6-8 weeks female mice were immunized by PIA, rSesC, and a mixture of them in four categorized. The control group received PBS as a basic solvent of antigens. All mice were boosted by each specific antigen two weeks after the first immunization. Immunized sera were collected in 14, 28 and 42 days after the first immunization. According to the obtained results in ELISA, evaluation of the total IgGs by checkerboard method, and diluted sera in 1: 200 determined as titers for all of the antigens. PIA and rSesC Immunized sera were not statistically significant when compared by the control 14 days after the first immunization. After the first booster dosage, increasing of the PIA and rSesC antibodies titers were observed, while titers of antibodies in $28(\mathrm{p}=0.0025)$ and $42(\mathrm{p}=0.0001)$ collected immune sera were statistically significant. Antibodies to a mixture of PIA and rSesC in all immunized sera were statistically significant.

Reports indicated that the presence of amine groups in the PIA structure increase titers in the first and second boosters is justifiable. The alum 
as an adjuvant could stimulate antibodies secretion and induction of Th2 immunity as well.

Since one of the most important characteristics of vaccine candidates is the in vitro and in vivo effects of them, in this study, the features of polyclonal secreted antibodies analyzed on biofilm formation under laboratory conditions. Data showed that immune sera after 14 days had a biofilm inhibitory effect, however, after the first and second booster, the effect of biofilm inhibition in the mixture group and other groups showed a significant difference compared with the control group in the last booster. Efficacy of antibodies in immunized sera showed that, at the first immunization for PIA $(\mathrm{p}=0.3466), \mathrm{rSesC}(\mathrm{p}=$ 0.371), biofilm inhibitory effect was not statistically significant when compared with the control group. Immunized sera by a mixture of PIA and rSesC in two weeks after the first immunization showed the biofilm inhibitory effect statistically significant $(p=0.0004)$. Biofilm inhibitory effect of antigens comparing with the different immunization eras (14/28 days) showed that the immunized sera by PIA, $\mathrm{rSesC}(\mathrm{p}=0.0314)$ and a mixture of them $(\mathrm{p}=$ 0.0003 ) were statistically significant as s well.

Reports indicated that the mixture of mentioned macromolecules had a good biofilm inhibitory effect. In our previous study using a mixture of PIA and $\mathrm{rSesC}$, the opsonic activity of arisen antibodies enhanced against biofilmforming S. epidermidis (24). In this study,

\section{References}

1. Lindsey EA, Brackett CM, Mullikin T, Alcaraz C, Melander C. The discovery of N-1 substituted 2-aminobenzimidazoles as zinc-dependent $S$. aureus biofilm inhibitors. MedChemComm. 2012;3(11):1462-5.

2. Liu GY. Molecular pathogenesis of Staphylococcus aureus infection. Pediatr Res. 2009;65(5 Pt 2):71R-77R.

3. Mousavi SF, Mirzaei B, Shaghaghi B, Jalali P, Setayesh T, Moosavi SH. Phenotypic and genotypic features of first biofilm forming nasopharyngeal colonized Streptococcus pneumoniae isolates. Iranian journal of microbiology. 2017;9(4):200-207. biofilm inhibition capability to PIA/rSesC mixture antibodies against biofilm-forming $S$. aureus was evaluated. Although opsonic activity and in vivo challenge for survival not cheeked at the current research but biofilm inhibition assay demonstrated that mixture of PIA and $\mathrm{rSesC}$, because of suitable decreasing of the biofilm against a wild type biofilmforming $S$. aureus, could be considered as a good candidate vaccine regarding inhibition of biofilm formation in both $S$. epidermidis an $S$. aureus.

We found that a PIA/rSesC mixture vaccine could inhibit the biofilm-formation process in $S$. aureus by eliciting high titer anti-PIA antibodies. It seems that this mixture could be employed in patients against the colonization and biofilm formation of this bacterium. We found that immunization of high-risk patients with a mixture of vaccine candidates or for treatment using monoclonal antibodies such as IgG2a could help eradicate bacterial biofilms. The preparation and purification of specific anti-PIA IgG2a are a possible means to inhibit medical device infections caused by $S$. epidermidis and $S$. aureus.

\section{Acknowledgements}

The authors wish to acknowledge the Pasteur Institute of Iran for funding. The authors are grateful for the support of colleagues in Bacteriology and Venom Departments in the Pasteur Institute of Iran.

4. van Belkum A. Staphylococcal colonization and infection: homeostasis versus disbalance of human (innate) immunity and bacterial virulence. Curr Opin Infect Dis. 2006;19(4):339-44.

5. Hogea C, Van Effelterre T, Cassidy A. A model-based analysis: what potential could there be for a $\mathrm{S}$. aureus vaccine in a hospital setting on top of other preventative measures?. BMC Infect Dis. 2014; 14:291.

6. Jones SM, Morgan M, Humphrey TJ, LappinScott H. Effect of vancomycin and rifampicin on meticillin-resistant Staphylococcus aureus biofilms. Lancet. 2001;357(9249):40-1. 
7. Adhikari RP, Karauzum H, Sarwar J, Abaandou L, Mahmoudieh M, Boroun AR, et al. Novel structurally designed vaccine for S. aureus $\alpha-$ hemolysin: protection against bacteremia and pneumonia. PLoS One. 2012;7(6):e38567.

8. Kuklin NA, Clark DJ, Secore S, Cook J, Cope LD, McNeely T, et al. A novel Staphylococcus aureus vaccine: iron surface determinant $B$ induces rapid antibody responses in rhesus macaques and specific increased survival in a murine $\mathrm{S}$. aureus sepsis model. Infect Immun. 2006;74(4):2215-23. 9. Shahmoradi M, Faridifar $P$, Shapouri R, Mousavi SF, Ezzedin M, Mirzaei B. Determining the Biofilm Forming Gene Profile of Staphylococcus aureus Clinical Isolates via Multiplex Colony PCR Method. Rep Biochem Mol Biol. 2019;7(2):181-188.

10. Paharik AE, Horswill AR. The staphylococcal biofilm: adhesins, regulation, and host response. Microbiol Spectr. 2016;4(2):10.

11. Cerca N, Jefferson KK, Oliveira R, Pier GB, Azeredo J. Comparative antibody-mediated phagocytosis of Staphylococcus epidermidis cells grown in a biofilm or in the planktonic state. Infect Immun. 2006;74(8):4849-55.

12. Maira-Litrán T, Kropec A, Goldmann DA, Pier GB. Comparative opsonic and protective activities of Staphylococcus aureus conjugate vaccines containing native or deacetylated staphylococcal poly-N-acetyl- $\beta$-(1-6)-glucosamine. Infect Immun. 2005;73(10):6752-62.

13. Shahrooei M, Hira V, Khodaparast L, Khodaparast L, Stijlemans B, Kucharíková S, et al. Vaccination with SesC decreases Staphylococcus epidermidis biofilm formation. Infect Immun. 2012;80(10):3660-8.

14. Shahrooei M, Hira V, Stijlemans B, Merckx R, Hermans PW, Van Eldere J. Inhibition of Staphylococcus epidermidis biofilm formation by rabbit polyclonal antibodies against the SesC protein. Infect Immun. 2009;77(9):3670-8.

15. Mack D, Nedelmann M, Krokotsch A, Schwarzkopf A, Heesemann J, Laufs R. Characterization of transposon mutants of biofilmproducing Staphylococcus epidermidis impaired in the accumulative phase of biofilm production: genetic identification of a hexosamine-containing polysaccharide intercellular adhesin. Infect Immun. 1994;62(8):3244-53.
16. Mirzaei B, Moosavi SF, Babaei R, Siadat SD, Vaziri F, Shahrooei M. Purification and evaluation of polysaccharide intercellular adhesion (PIA) antigen from staphylococcus epidermidis. Curr Microbiol. 2016;73(5):611-617.

17. Mirzaei B, Mousavi SF, Babaei R, Bahonar S, Siadat SD, Ardestani MS, et al. Synthesis of conjugated PIA-rSesC and immunological evaluation against biofilm-forming Staphylococcus epidermidis. J Med Microbiol. 2019;68(5):791-802.

18. Otto M. Staphylococcus epidermidisthe'accidental'pathogen. Nat Rev Microbiol. 2009;7(8):555-567.

19. Farjah A, Owlia P, Siadat SD, Mousavi SF, Ardestani MS, Mohammadpour HK. Immunological evaluation of an alginate-based conjugate as a vaccine candidate against Pseudomonas aeruginosa. APMIS. 2015;123(2):175-83.

20. Amini V, Kazemian H, Yamchi JK, Feyisa SG, Aslani S, Shavalipour A, et al. Evaluation of the Immunogenicity of Diphtheria Toxoid Conjugated to Salmonella Typhimurium-Derived OPS in a Mouse Model: A Potential Vaccine Candidate Against Salmonellosis. Iran Red Crescent Med J. 2016;18(7):e34135.

21. Hickman DL, Johnson SW. Evaluation of the aesthetics of physical methods of euthanasia of anesthetized rats. J Am Assoc Lab Anim Sci. 2011;50(5):695-701.

22. Christensen GD, Simpson WA, Younger JJ, Baddour LM, Barrett FF, Melton DM, et al. Adherence of coagulase-negative staphylococci to plastic tissue culture plates: a quantitative model for the adherence of staphylococci to medical devices. J Clin Microbiol. 1985;22(6):996-1006.

23. Stepanović S, Vuković D, Hola V, Bonaventura GD, Djukić S, Ćirković I, et al. Quantification of biofilm in microtiter plates: overview of testing conditions and practical recommendations for assessment of biofilm production by staphylococci. APMIS. 2007;115(8):891-9.

24. Kobayashi N, Taniguchi K, Kojima K, Urasawa S, Uehara N, Omizu Y, et al. Analysis of methicillin-resistant and methicillin-susceptible Staphylococcus aureus by a molecular typing 
method based on coagulase gene polymorphisms. Epidemiol Infect. 1995;115(3):419-26.

25.Hu J, Xu T, Zhu T, Lou Q, Wang X, Wu Y, et al. Monoclonal antibodies against accumulationassociated protein affect EPS biosynthesis and enhance bacterial accumulation of Staphylococcus epidermidis. PloS one. 2011;6(6):e20918.

26.Krasowska A, Sigler K. How microorganisms use hydrophobicity and what does this mean for human needs?. Front Cell Infect Microbiol. 2014;4:112.
27.Marraffini LA, DeDent AC, Schneewind O. Sortases and the art of anchoring proteins to the envelopes of gram-positive bacteria. Microbiol Mol Biol Rev. 2006;70(1):192-221.

28.Christner M, Franke GC, Schommer NN, Wendt $\mathrm{U}$, Wegert $\mathrm{K}$, Pehle $\mathrm{P}$, et al. The giant extracellular matrix-binding protein of Staphylococcus epidermidis mediates biofilm accumulation and attachment to fibronectin. Mol Microbiol. 2010;75(1):187-207. 